\title{
DIOP, Babacar Mbaye; DIENG, Doudou (Org.). A Consciência Histórica Africana. Luanda: Edições Mulemba da Faculdade de Ciências sociais da Uni- versidade Agostinho Neto, 2014, 220 p.
}

Eleonora Beatriz Ramina Apolinário

Giulia Aniceski Manfredini Marcelo Augusto Farias Martins Mariana Mehl Gralak Rebeca Nogueira Vilodres ${ }^{1}$

A Consciência Histórica Africana, organizado por Babacar Mbaye Diop (professor no departamento de Filosofia da Universidade Cheikh Anta Diop, Senegal) e Doudou Dieng (doutor em Filosofia pela Universidade de Rouen, França), é uma compilação de textos de autores das áreas de história, física, letras, entre outras, evidenciando a construção Ocidental sobre o que é a África, elucidando os processos que induziram à uma concepção de existência de um continente atemporal e ahistórico. Expondo esse processo, os autores da coletânea defendem caminhos para que essa imagem deixe de existir, sendo o principal deles a retomada da consciência histórica africana, fazendo jus ao título da obra.

A obra é iniciada evidenciando: a África Negra encontra-se em uma situação de precariedade e exposição perante o Ocidente, o qual busca manter seu controle sobre o povo negro por intermédio da falsifi-

\footnotetext{
${ }^{1}$ Estudantes do sexto período de graduação em História (bacharelado e licenciatura) pela UFPR.
} 
cação e forjamento de fatos históricos. Ou seja, diante a constatação de que uma civilização como a egípcia seria fruto de um povo africano, e não do ocidente, os ocidentais - sabendo que a tomada da consciência histórica dificultaria as investidas de controle, manipulação e imposição - forjaram uma historiografia desfavorável aos nativos do continente africano. O resultado de tal embate é a concepção de uma África ahistórica, sem desenvolvimento, do homem africano como aquele que nunca contribuiu para a humanidade. Enquanto isso, os ocidentais se colocariam como recuperadores da história do continente por intermédio de missionários, militares, administradores e mesmo pesquisadores, como demonstra Thiago Stering Moreira da Silva, formado em História pela UFJF, que reafirmava a percepção eurocêntrica da África. Sob esse quadro, Diop defende que a verdade e a memória histórica poderiam engrenar revoltas e a formação de uma consciência histórica que inseriria o continente na história mundial, deixando de negligenciá-lo. $\mathrm{O}$ africano deve, portanto, analisar o passado de seu povo. A história da África deve ser apresentada não como a história de europeus no continente, mas partindo da experiência de populações africanas em contato com eles. Assim, a partir desta concepção historiográfica, outras obras africanas enriquecem o debate sobre a construção da história da África, como a Coleção da História Geral da África - Metodologia e pré história da África, organizado por Ki Zebo, de oito volumes, além da obra Historiografia da História de África de Manuel Difula.

Bwemba Bong', membro do Círculo Samory e do Groupe de Réflexion Sur la Culture Africaine pour la Renaissance du Peuple Noir, 
aponta que a decadência dos grandes impérios do continente - como a civilização egípcia - deve ser analisada em tal retorno ao passado e pode ser resumida tanto em causas internas quanto externas. $\mathrm{O}$ autor se volta à necessidade de escutar as narrativas de antigos eruditos e absorver seu saber. A quebra de tal silêncio, conclui, poderia salvar a África do poderio estrangeiro, e o sistema de transmissão de conhecimentos e tal tradição oral devem ser reformulados de forma a torná-los acessíveis para as novas gerações de historiadores da África. Além da importância da cultura oral, os povos africanos têm uma relação diferente da relação de dominação do homem sobre a natureza mantida pelos ocidentais: a concepção africana perpetuou a visão do ser humano integrado à natureza, não dominador dela. Além desses aspectos, a ética contra a acumulação de riquezas, a exclusão de promoção social, a crença de que ricos são abençoados por deus e a visão da morte como passagem para outra vida, quando comparados à cultura ocidental, passam a ser considerados outros fatores internos que geram uma inércia mediante os acontecimentos e devem, para o autor, desaparecer.

Diante de tais características, o autor evidencia a necessidade do africano de refletir sobre sua história. A falta de patriotismo, por sua vez, levaria a traições, à existência de uma prejudicial ganância e a uma confiança demasiada no estrangeiro que corromperiam a consciência histórica tão necessária para as sociedades africanas. Dentre tais formas de traição, a renúncia à independência e a subjugação às potências mundiais seriam outra prova de que os países africanos não podem ser mais um prolongamento destas. A garantia do futuro e da unidade política do 
continente, conclui o pesquisador, só ocorrerá por tal tomada de consciência e mobilização por parte do africano. Um exemplo desse processo de dominação externa sobre o povo africano trazido pelo historiador Momar Mbaye é a Guerra do Biafra, um processo de evolução política perpassado por extrema violência que marcou a Nigéria sete anos após a sua independência, analisando a cobertura que a imprensa internacional fez do conflito, manipulando as mídias do hexágono através de agentes pró-biafrenses.

O argumento central do livro é reforçado por Bernard Zongo, utilizando o intelectual senegalês Cheikh Anta Diop. Afirma que a restauração da consciência histórica do homem negro consiste numa luta constante contra as instâncias de dominação, que tentam de diversas maneiras preservar o seu estatuto. Seus exemplos são os "pseudo-científicos" ou "pseudo-humanistas" Voltaire, Hegel, Gobineau, Bruhl e Hume, que no século XIX se aplicaram a legitimar moral e filosoficamente a "inferioridade intelectual" dos negros, travestindo dados científicos para corroborar com uma ideologia de submissão e dominação desse povo. Analisando de um ponto de vista linguístico, o autor introduz o conceito de glatofagia: a ideia de que as línguas, culturas e comunidades dos outros existem apenas para provar a superioridade das línguas ocidentais, sendo fósseis da evolução das mesmas, afirmando que toda a linguística africanista francesa carrega os germes de uma ideologia glatofágica.

Reconstruindo a consciência histórica, a segunda parte da obra é denominada “As Origens egípcias da civilização africana". Ressalta o trabalho de Cheikh Anta Diop, dedicado à uma análise sobre as relações 
do Egito com a África Negra que tanto foi impedida pelo colonizador. O contexto inicial é a "partilha da África" promulgada pelo pacto de Berlim, e a dominação de seu povo por países europeus. Diop mostra como se deram as relações de poder, especialmente o método dos europeus de legitimar seu domínio através da filosofia, além de todo o poderio econômico, militar e bélico que insultava a cultura existente nos territórios africanos. A construção do Egito branco demonstra a concretização de uma política racista que subjugou o negro como incapaz de construir e produzir avanços científicos. A consciência histórica africana é, portanto, uma forma de resistir às filosofias infelizmente fecundas que legitimou a opressão por parte dos brancos - que fizeram o indigno trabalho de produzir uma ciência que solidificou a desigualdade.

É necessário resgatar e reconstituir as relações Egito - "África Negra" para estimular a consciência histórica africana, além de buscar a relação África - Mundo. Cheikh Anta Diop separa vários aspectos que podem resgatar tal relação, como a origem do homem (no sentido antropológico), e os aspectos culturais, sociológicos, geográficos, evolutivohistóricos que aproximam a África-Negra do Egito e do mundo. Aponta também a importância do surgimento da Escola africana de Egiptologia para a resistência negra. O professor afirma ainda a existência de uma unidade entre as culturas egípcias e as da áfrica-negra realizando uma comparação lexical entre egípcio antigo e as línguas negro-africanas como fula, wolof, serer, soninquê, bamba, dogon.

Cheikh Anta Diop defende a necessidade de uma escrita sobre a história da antiguidade africana, que abranja as antigas sociedades, mas 
destaca a impossibilidade dessa narrativa ser realizada por indivíduos não-africanos. A construção da antiguidade dessas sociedades ocorreria a partir de documentos escritos egípcios, cartagineses e gregos, fontes arqueológicas localizadas principalmente no Vale do Nilo, e os quadros rupestres. Assim, o autor Babaccar Sall enfatiza a busca de uma história africana, contada por africanos, a partir de fontes africanas. E evidencia que o conhecimento das antigas sociedades é fundamental para a construção da consciência negra, e não uma busca por um passado grandioso forjado.

Por fim, a temática se volta para as teorias filosóficas africanas, que, segundo a pesquisa do Pr. Obenga, se inserem na história geral do continente a partir dos estudos do período faraônico egípcio - na criação de uma língua tão complexa quanto os hieróglifos e sua forma de pensar. Para o professor, diferente do que afirmam os pensadores ocidentais, o Egito e a Etiópia criaram formas de organização e sociedades muito particulares e desenvolvidas. $\mathrm{O}$ conhecimento destas teorias filosóficas africanas contribui para a construção de uma consciência própria, da mesma maneira que a antiga Grécia é um pilar para o conhecimento europeu, o antigo Egito se consolida para a África. Portanto é necessário inserir o pensamento africano dentro da história do pensamento mundial, não o tratar de maneira segregada ou inferior. Outras obras de pensadores africanos enfatizam a existência de uma filosofia própria africana e sua relevância tanto na construção da identidade do continente, como na discussão com a história europeia. Tal como a obra 
de Marcien Towa, um filósofo camaronês, denominada $A$ ideia de filosofia negro-africana e o livro A Invenção da África de V.Y. Mudimbe.

$\mathrm{Na}$ terceira e última parte do livro, "O contributo da comunidade negra e do Egito para a civilização", os autores trazem provas, baseados no conhecido filósofo Platão, de que o Egito sempre foi posto como parte da África. Primeiramente, Jean-Paul Mbelek afirma, como ideia recorrente em todo o texto, que a construção da Europa como uma cultura universal originariamente grega foi embasada em uma mentira cultural, assim como toda a história científica. Tal ato negligenciou, e ainda negligencia, toda a produção de conhecimentos africanos.

Quase ironicamente, ao discorrer sobre o Egito na obra de Platão, Théophile Obenga, outro autor da coletânea, expõe que os próprios gregos, retratados pelo Ocidente como gênese da civilização, atribuíam tal fato aos egípcios. Além disso, para evidenciar a omissão do continente africano como parte da História desde os primórdios das produções na Antiguidade, o autor cita um fato no mínimo curioso: 12, das 28 obras que incluem os Diálogos de Platão, cita o Egito. Porém, como tudo que envolve a África e serve para provar sua participação em produções filosóficas que a retiram do papel de inércia pintado pelos ocidentais, pouco se fala sobre tal inclusão. Tal crítica é realizada também pelo autor V. Y. Mudimbe, em sua obra A Ideia de África, em que traça uma conexão entre o mundo greco-romano ao continente africano, problematizando a tradução dos escritos de Filóstrato e a articulação feita pelos Europeus na construção de conceitos sobre a África. 
Além disso, mais feitos são atribuídos aos africanos, segundo Obenga: a invenção das ciências matemáticas, a invenção do zero. A gênese da civilização mundial atribuída à África, como exposto no parágrafo anterior, é comprovada por fósseis encontrados não no Egito, como pode se imaginar numa primeira leitura, mas no Quênia, Etiópia e África do Sul. Sendo assim, Mbelek defende que o processo de hominização ocorreu somente na África por muito tempo.

Convergindo com a ideia central do livro - a retomada da consciência histórica como forma de resistência - consideramos de fundamental importância que o estudo sobre a história africana receba tanto mais investimento, como incentivos. Além das provas evidenciadas no livro, que demonstram os percalços para que tal empresa seja feita, o próprio grupo encontrou dificuldades ao pesquisar termos, conceitos e até mesmo as origens dos diversos escritores que produziram o livro. Quando muito, tais informações eram encontradas em outras línguas (não por acaso, majoritariamente a língua francesa, devido ao imperialismo Francês sobre a África). Portanto, os processos de domínio sobre o continente africano não estão delimitados apenas aos séculos passados, mas são recorrentes até os dias de hoje. Tanto na ocultação de informações sobre a África e as produções científicas que lá ocorrem, como na forma que ela é retratada dentro de livros escolares, que geralmente expõem apenas o Egito como grande civilização, retratando-o como branco e induzindo ao equívoco de considerá-lo europeu, negligenciando a formação de todo o continente Africano por diversos séculos, até que colonialismo o coloque como fonte de escravos. 
Cadernos de Clio, Curitiba, v. 8, $\mathrm{n}^{\mathrm{o}}$ 1, 2018

\section{Bibliografia}

DIFUILA, Manuel Maria. "Historiografia da História de África". In: Actas do Colóquio 'Construção e Ensino da História de África'. Lisboa: Linopazas, 1995.

DIOP, Babacar Mbaye; DIENG, Doudou (Org.). A Consciência Histórica Africana. Luanda: Edições Mulemba da Faculdade de Ciências sociais da Universidade Agostinho Neto, 2014.

KI-ZEBO, Joseph (Org). História Geral da África: Metodologia e préhistória da África. São Paulo: Editora Ática/Paris: UNESCO, 1982.

MUDIMBE, Valentin Yves. A invenção da África: Gnose, filosofia e a ordem do conhecimento. Mangualde, Luanda: Edições Pedago; Edições Mulemba, 2013.

MUDIMBE, Valentin Yves. A Ideia de África. Portugal: Edições Pedago, 2014.

SILVA, Thiago Stering Moreira da. Caminhos e descaminhos da historiografia da História da África (1840-1990). Trabalho Monográfico de Graduação em História - Instituto de Ciências Humanas, Universidade Federal de Juiz de Fora, 2010. Disponível em $<$ http://www.ufjf.br/historia/files/2013/11/2010-Caminhos-edescaminhos-da-historiografia-da-Hist $\% \mathrm{C} 3 \% \mathrm{~B} 3$ ria-da- $\% \mathrm{C} 3 \% 81$ frica1840-.pdf>. Acesso em 4 set. 2018.

TOWA, Marcien. A ideia de uma Filosofia Negro-Africana. Trad. Roberto Jardim da Silva. Belo Horizonte: Nandyala; Curitiba: NEABUFPR, 2015.

Recebido em: 21/08/2018

Aceito em: 17/09/2018 